\title{
The process of oncology nurse practitioner patient navigation: navigation in the chemotherapy suite, navigation tools revisited
}

\section{Mini review}

Research pertaining to the role and process of Oncology Nurse Practitioner (ONP) patient navigation in the chemotherapy suite is limited, yet it is maintained that management of patients receiving chemotherapy requires a team effort Weiss et al., ${ }^{1}$ and that the navigation process requires the use of navigation tools Johnson ${ }^{2}$ A recent ethnographic study in the United Kingdom (UK), looked at the scope of clinical practice of nurse-lead clinics which included both chemotherapy nurses, and advanced practice nurses (APN's). It was found that different levels of care existed amongst the clinics, and that these levels of care were driven by the level of nursing autonomy and scope of practice, which was heavily influenced by medical consultants Farrell et al. ${ }^{3}$ Studies have confirmed the importance of good working relations between advanced practice nurses administrative supervisors, and medical staff Johnson ${ }^{4}$ Farrell et al. ${ }^{3}$ The role and responsibilities of ONP's in the chemotherapy suite requires clear delineation, and negotiation of the role with the physician. Literature has shown that ill coordinated care for chemotherapy patients can hinder high level collaborative relationships, and negatively impact patient care Bunnell et al. ${ }^{5}$

Several tools have been identified as successful in improving patient navigation in the chemotherapy suite, which foster collaborative practice. These include: the team huddle, gerontological assessments tools, and this authors care co-ordination work-sheet tool entitled the Chemotherapy Care Co-ordination Rounding tool.

\section{The team huddle}

Quality cancer care is patient centered, safe, smooth and efficient, timely, and well-coordinated. It utilizes an interprofessional team approach with the integration of evidence-based practices, which are continuously re-evaluated with the goal of continuously improving care Institute of Medicine. ${ }^{6}$ The team huddle is one such tool; and in fact has been identified as a successful means of facilitating team communication, in addition to addressing root cause analyses of chemotherapy associated sentinel events Blough \& Walrath Morrissey et al., ${ }^{8}$ Bunnell et al., ${ }^{5}$ Weiss et al. ${ }^{1}$ For example, Bunnell et al., ${ }^{5}$ as part of a process improvement initiative identified four major issues arising from lack of a team approach to oncology chemotherapy patients. These included:

i. Miscommunication of chemotherapy order changes on the day of treatment;

ii. Issuing orders on treatment days without concurrent physician appointments;

iii. Poor follow-up with team members about active patient issues; and

iv. Conflict between providers and staff. The institution utilized a formal train-the trainer team training model for oncology staff
Volume 9 Issue 4 - 2018

Frances Mary Johnson

Carl R. Darnall Army Medical Center, USA

Correspondence: Frances Mary Johnson, Carl R Darnall Army Medical Center, 36065 Santa Fe Avenue, Fort Hood,TX 76544 USA,Tel 28I-300-2635, Email roseypumpkin@mail.comt

Received: July 0I, 2018 | Published: July II, 2018

caring for breast cancer patients, which had a favorable impact on all of these issues. The training consisted of various interventions and tools; one of which was regular interdisciplinary NP/PA huddles, which served to address the complex care issues of patients undergoing chemotherapy Bunnell et al. ${ }^{5}$

Standardized assessment tools for the chemotherapy patient are essential, and serve as an objective measure for gauging the patients' condition as well as response to treatment. The American Association of Clinical Oncology (ASCO) identified the importance of standardized reliable and valid tools, and decision making models for the geriatric patient based on expert consensus Mohile et al. ${ }^{9}$ They maintain that providers are obligated to develop integrated plans, based on individual risk factors that can contribute to adverse outcomes, which include nononcologic comorbidities Mohile et al. ${ }^{9}$ Some of the recommended tools are the Geriatric Depression Scale (GDS); Yesavage et al., ${ }^{10}$ and the Mini-Cog Borson, n.d. ${ }^{11}$ Borson et al., ${ }^{12}$ or the Blessed Orientation-Memory-Concentration test (BOMC) DYSmd ${ }^{\mathrm{TM}}$, n.d. ${ }^{13}$ Katzman $\mathrm{R}^{14}$ which measure depression and cognition respectfully. Assessments should include Instrumental Activities of Daily Living (IADLs) Moffitt, n.d., ${ }^{15}$ unintentional weight loss, nutrition (Nestle Nutrition, n.d.), and presence of falls, as well as other co-morbidities. Other recommendations include but are not limited to use of the Cancer and Aging Research Group (CARG), CARG, n.d. ${ }^{16}$ Hurria $^{17}$ or The Chemotherapy Risk Assessment Scale for High Age Patients (CRASH) tools which measure chemotherapy toxicity. Any of these tools can be useful for the ONP in the chemotherapy treatment suite for gauging the patient's suitability and response to treatment. They also serve to stimulate group discussion towards refining the patient's treatment plan. The author directs the reader to the original ASCO guidelines for a comprehensive list of tools and decision making models Mohile et al. ${ }^{9}$

The process on ONP patient navigation includes assessing, diagnosing, triaging, and guiding the patient to the next step Johnson. ${ }^{2}$ This author has found the Chemotherapy Care Co-ordination Rounding tool to be useful when used concomitantly with the team huddle (Figure 1). Members can include but are not limited to an 
ONP or PA, oncologist, oncology nurses, and pharmacist. The tool is depicted in figure one and consists of a thumb nail sketch of the patient's profile. It includes number of chemotherapy cycles, provider visit dates, due date for next provider assessment, restaging results, due dates for restaging, screening tools used with results, co-morbidities, and outcomes. This very simple tool has been used by this provider as an information guide for staff. It creates an atmosphere for mutual exchange between care givers. It tracks diagnostic tests, and tumor markers; serves to track, record, and expedite changes in the physician treatment plan, and facilitates early intervention; the goal being a favorable treatment response. Group discussions that ensue stimulate a forum for collaborative interdisciplinary education. More research is needed in reference to the development of tools such as this which incorporate standardized chemotherapy measurement tools tailored for the chemotherapy patient. ${ }^{18-22}$

\begin{tabular}{|c|c|c|c|c|c|c|c|c|c|}
\hline Name/Date & Diagnosis & $\begin{array}{l}\text { \# of Cycles } \\
\text { Present/Total }\end{array}$ & $\begin{array}{l}\text { Last MD } \\
\text { visit }\end{array}$ & $\begin{array}{l}\text { Next MD } \\
\text { Visit }\end{array}$ & $\begin{array}{l}\text { Restaging } \\
\text { results }\end{array}$ & $\begin{array}{l}\text { Restaging } \\
\text { date }\end{array}$ & $\begin{array}{l}\text { Misc. } \\
\text { Distress Screen } \\
\text { Barriers } \\
\text { Assessment Tools }\end{array}$ & $\begin{array}{l}\text { Comorbidity } \\
\text { status }\end{array}$ & $\begin{array}{l}\text { Outcome } \\
\text { goals }\end{array}$ \\
\hline ummary & & & & & & & & & \\
\hline
\end{tabular}

Figure I Chemotherapy Rounding Tool.

\section{Conclusion}

In conclusion, there is a paucity of literature pertaining to the role and process of ONP patient navigation in the chemotherapy suite, yet it is maintained that management of patients receiving chemotherapy requires a team effort. Three recommendations have been put forth which utilize an inter professional team approach through the integration of evidence-based practice guidelines. The team huddle, a proven intervention for fostering collaborative relations, standardized tools which have proven reliability and validity for gauging the condition of elderly chemotherapy patients, and this author's example of the Chemotherapy Care Co-ordination Rounding tool, can all be combined to work towards this aim, in addition to creating a milieu of ever evolving patient care excellence.

\section{Acknowledgements}

None.

\section{Conflict of interest}

Author declares that there is no conflict of interest.

\section{References}

1. Weiss BD, Scott M, Demmel K, et al. Significant and sustained reduction in chemotherapy errors though improvement science. Journal of Clinical Oncology. 2017;35(Suppl 8S; abstract 37).

2. Johnson FM. The Process of Oncology Nurse practitioner Patient Navigation: A Grounded Theory Approach, Navigation Tools. Journal of Cancer Prevention and Current Research. 2017;8(7).

3. Farrell C, Walshe C, Molassiotis A. Are nurse-led chemotherapy clinics really nurse-led? An ethnographic study. International Journal of Nursing Studies. 2017;69:1-8.

4. Johnson FM. The process of oncology nurse practitioner patient navigation: A grounded theory approach, carving the role. Journal of Neoplasm. 2018;3(1:2):1-9.

5. Bunnell CA, Gross AH, Weingart SN, et al. High performance teamwork training and systems redesign in outpatient oncology. British Medical Journal Quality Safety. 2013;22(5):405-413.

6. Institute of Medicine. Delivering high-quality cancer care: Charting a new course for a system in crisis. Washington, DC: National Academies Press. 2013.

7. Blough CA, Walrath JM. Improving patient safety and communication through care rounds in a pediatric oncology outpatient clinic. Journal of Nursing Care Quality. 2007;22(2):159-163.
8. Morrissey L, Nixon C, Giarrusso. The chemo huddle: A strategy to minimize errors and maximize chemotherapy safety. European Journal of Oncology Nursing. 2011;15(3):278.

9. Mohile SG, Dale W, Somerfield MR, et al. Practical assessment and management of vulnerabilities in older patients receiving chemotherapy: ASCO guideline for geriatric oncology summary. Journal of Oncology Practice. Advance online publication; 2018.

10. Yesavage JA, Brink TL, Rose TL, et al. Development and validation of a geriatric depression screening scale: A preliminary report. Journal of Psychiatric Research. 1982-1983;17(1):37-49.

11. Borson S (n.d.). The Mini-Cog(C)

12. Borson S, Scanlan JM, Chen P, et al. The Mini-Cog as a screen for dementia: Validation in a population-based sample. Journal of the American Geriatric Society. 2003;51(10):1451-1454.

13. DYSmd ${ }^{\mathrm{TM}}$ (n.d.). The Blessed Orientation-Concentration-Memory-Test (BOMT).

14. Katzman R, Brown T, Fuld P, et al. Validation of a short orientationmemory-concentration test of cognitive impairment. American Journal of Psychiatry. 1983;140(6):734-739.

15. Moffit Cancer Center (n.d.). Instrumental Activities of Daily Living (IADL) Scale.

16. Cancer and Aging Research Group (CARG). (n.d).

17. Hurria A, Togawa K, Mohile SG. Predicting chemotherapy toxicity in older adults with cancer: A prospective multicenter study. Journal of clinical Oncology. 2011;29(25):3457-3465.

18. Cancer and Aging Research Group (CARG). (n.d.). Prediction Tool.

19. CRASH. Senior Adult Oncology Program Tools: CRASH Score. Moffit Cancer Center. 2017.

20. https://moffitt.org/for-healthcare-providers/clinical-programs-andservices/senior-adult-oncology-program/senior-adult-oncology-programtools/

21. Extermann M, Boler I, Reich RR, et al. Predicting the risk of chemotherapy toxicity in older patients: the Chemotherapy Risk Assessment Scale for High-Age Patients (CRASH) score. Cancer. 2012;118(13):3377-3386.

22. Nestle Nutrition (n.d.). Tools and Indexes. MNA® Mini Nutritional Assessment. 